\title{
Redes de ódio: A homofobia no Facebook
}

\author{
Hate networks: Homophobia on Facebook
}

\author{
Redes de odio: La homofobia en Facebook
}

\author{
Lawerton Braga da Silva* \\ Universidade Federal da Paraíba - UFPB, João Pessoa, Paraíba, Brasil
}

Renata Lira dos Santos Aléssio**

Universidade Federal de Pernambuco - UFPE, Recife, Pernambuco, Brasil

\begin{abstract}
RESUMO
A homofobia é um fenômeno relevante que está presente nas relações sociais, por meio de crenças, emoções, ideologias e posicionamentos. Este artigo analisou as diferentes formas de expressões da homofobia a partir de uma postagem no Facebook da página "Quebrando o Tabu" à luz da teoria das representações sociais. As relações intergrupais, presentes no coração da teoria, se constituíram como processos norteadores das discussões. A partir de um vídeo a respeito da homossexualidade foram selecionados 1.592 comentários. Os dados foram analisados pelo software IRAMUTEQ por meio de uma classificação hierárquica descendente que resultou em quatro classes de discursos. A Classe 1 (40\%), denominada, "Respeito"; a Classe 2 (22.1\%), "Debate político-ideológico"; a Classe 3 (12.9\%), "Influência da homossexualidade para as crianças" e; por fim, a Classe 4 (25\%), denominada de "Acusação aos homossexuais de deturpação da igreja". Os resultados evidenciaram em todas as classes a existência de conflitos entre grupos; diferenças entre as expressões homofóbicas; um discurso que justificava os posicionamentos por meio dos valores igualitário, além de evidenciar que as expressões contra homossexuais estavam ancoradas em três explicações, a saber, bio-religiosas, ético-morais e psicossociais.

Palavras-chave: preconceito, homossexualidade, Facebook, representações sociais, relações intergrupais.
\end{abstract}

\begin{abstract}
Homophobia is a relevant phenomenon that is present in social relations, through beliefs, emotions, ideologies, and opinions. This article has analyzed the different forms of homophobic expressions from a post on a fanpage called "Quebrando o tabu" (Breaking taboos) in the light of the Social Representation Theory. The intergroup relations, present in the heart of the theory, guided the discussions. From a video about homosexuality we selected 1.592 comments. The data were analyzed by the software IRAMUTEQ by means of a downward hierarchical classification that resulted in four classes of discourses. Class 1 (40\%), named, "Respect"; the Class 2 $(22.1 \%)$, "the political-ideological debate"; the Class $3(12.9 \%)$, "the Influence of homosexuality on children and; finally, Class $4(25 \%)$, called "Accusing homosexuals of misrepresenting the church." The results
\end{abstract}


evidenced in all the classes the existence of conflicts between groups; differences among the expressions of homofobia; a discourse that justified their opinions by means of equal rights, in addition to showing that the expressions against homosexuals were anchored in three explanations, namely, the bio-religious, ethical-moral and psychosocial.

Keywords: prejudice, homosexuality, Facebook, social representations, intergroup relations.

\begin{abstract}
RESUMEN
La homofobia es un fenómeno relevante que está presente en las relaciones sociales, por medio de creencias, emociones, ideologías y posicionamientos. Este artículo analizó las diferentes formas de expresiones de la homofobia a partir de una entrada en Facebook de la página "Rompiendo el Tabú" a la luz de la teoría de las representaciones sociales. Las relaciones intergrupales, presentes en el corazón de la teoría, se constituyeron como procesos orientadores de las discusiones. A partir de un vídeo acerca de la homosexualidad se seleccionaron 1.592 comentarios. Los datos fueron analizados por el software IRAMUTEQ por medio de una clasificación jerárquica descendente que resultó en cuotro clases de discursos. La Clase 1 (40\%), denominada, "Respeto"; la Clase 2 (22.1\%), "Debate políticoideológico"; la Clase 3 (12.9\%), "Influencia de la homosexualidad para los niños y; por último, la Clase 4 (25\%), denominada "Acusación a los homosexuales de tergiversación de la iglesia". Los resultados evidenciaron en todas las clases la existencia de conflictos entre grupos; diferencias entre las expresiones homofóbicas; un discurso que justificaba los posicionamientos por medio de los valores igualitarios, además de evidenciar que las expresiones contra homosexuales estaban ancladas en tres explicaciones, a saber, bio-religiosas, ético-morales y psicosociales.
\end{abstract}

Palabras clave: prejuicio, la homosexualidad, Facebook, representaciones sociales, relaciones intergrupales.

No Brasil, segundo o último relatório do Grupo Gay da Bahia (GGB), em 2017 morreram 445 pessoas LGBT (lésbicas, gays, bissexuais e transexuais): 387 assassinatos e 58 suicídios. Esse é o maior registro de mortes durante os 38 anos de atuação do grupo (GGB, 2017). Junto a isso, percebe-se o crescimento de maneira exponencial do conservadorismo e do fundamentalismo religioso ao longo dos últimos anos (J inkings, Doria, \& Cleto, 2016).

A homofobia é um fenômeno complexo e sua erradicação, assim como de outras formas de preconceito, pode levar muito tempo para ser alcançada. No Brasil, por exemplo, não existe um banco de dados ou relatório oficial por parte do governo no que diz respeito aos crimes de motivação homofóbica. Segundo o GGB (2017), o descaso que se vive no país é prova da incompetência e da homofobia governamental pela qual passamos.

O estudo do preconceito passou a ser interesse da psicologia na década de 1920, intensificando-se no começo dos anos 1950. Fernandes (2011) propôs um quadro atualizado dos estágios pelos quais o estudo do preconceito foi sendo desenvolvido ao longo do tempo, principalmente no campo da psicologia. A autora dividiu em 7 
momentos que são: (1) psicologia das raças (Garth, 1930); (2) fatores psicológicos como origem do preconceito (Bogardus, 1928); (3) estágio dos processos psicodinâmicos (Dollard, Doob, Miller, Mowrer, \& Sears, 1939); (4) estágio das teorias da personalidade preconceituosa (Adorno, Frenkel-Brunswik, Levinson \& Sanford, 1950); (5) estágio sociocultural (Tajfel, 1982); (6) estágio dos processos psicológicos fundamentais (McConahay \& Hough, 1976); e (7) o preconceito como fenômeno multifocal (Camino, 1996; Doise, 1982). Concomitantemente, surgiram suas novas formas de expressão mais sutis e mascaradas (Pettigrew \& Meertens, 1995; Turra \& Venturi, 1995).

Lacerda, Pereira e Camino (2002, p.166) definem o preconceito como "uma forma de relação intergrupal onde, no quadro específico das relações de poder entre grupos, desenvolvem-se e expressam-se atitudes negativas e depreciativas além de comportamentos hostis e discriminatórios em relação aos membros de um grupo por pertencer a esse grupo". Ressalta-se nessa definição que o preconceito pode levar à discriminação, caracterizada por ações e comportamentos, e não apenas atitudes. No princípio, as pesquisas estavam centradas nos aspectos étnico-raciais e, somente, na década de 1970, a homofobia passou a ser objeto de estudo.

$\mathrm{Na}$ literatura psicológica, o termo "homofobia" foi utilizado pela primeira vez por Smith em 1971, referindo-se a uma aversão de caráter psicológico à homossexualidade. Entretanto, popularizou-se em 1972 com o psicólogo americano George Weinberg. Até hoje, sua definição e conceito têm sido motivo de disputas (Costa \& Nardi, 2015; Junqueira, 2012), e expressões como homossexismo (Lehne, 1976); homonegativismo (Hudson \& Ricketts, 1980); homopreconceito (Logan, 1996); preconceito sexual (Herek, 2000); estigma sexual (Herek, 2007); homofobia (Borrilo, 2009); e preconceito contra diversidade sexual (Costa \& Nardi, 2015), são utilizadas para estudar o mesmo fenômeno.

Seguindo uma tendência atual dos estudos sobre o preconceito contra homossexuais, além de ser um termo popularizado no senso comum, esta pesquisa adota o termo "homofobia", definido por Borrillo (2009) como:

A hostilidade geral, psicológica e social àqueles ou àquelas que supostamente sentem desejo ou têm relações sexuais com indivíduos de seu próprio sexo. Forma particular de sexismo, a homofobia renega igualmente todos aqueles que não se enquadram nos papéis determinados para seu sexo biológico. Construção ideológica que consiste na promoção constante de uma forma (hetero) em detrimento de outra (homo), a homofobia organiza uma hierarquização das sexualidades, o que tem consequências políticas (Borrillo, 2009, p. 27). 
Segundo Junqueira (2012, p. 3), esse termo "costuma ser empregado quase que exclusivamente em referência a conjuntos de emoções negativas (tais como aversão, desprezo, ódio, desconfiança, desconforto ou medo) em relação a pessoas homossexuais ou assim identificadas". As definições de homofobia incorporam, basicamente, duas dimensões, postas de maneira isolada ou combinada, a depender da compreensão. Segundo Rios (2007), uma diz respeito à dinâmica subjetiva desencadeadora da homofobia (medo, aversão e ódio), resultando no preconceito contra homossexuais. Outra dimensão sublinha suas raízes sociais, culturais e políticas. A dimensão proposta por Borrillo (2009) considera os processos individuais, as relações intergrupais, as relações de poder e de influência social, aspectos importantes para compreender 0 preconceito de forma multifocal.

Utilizou-se a teoria das representações sociais, "um sistema de valores, noções e práticas que proporcionam aos indivíduos os meios para orientar-se no contexto social e material" (Silva, Constantito, \& Premaor, 2011, p. 235), como aporte teórico que, segundo Pereira et al. 2011 e Lacerda et al. 2002, está na gênese e base das expressões do preconceito.

Cada grupo social possui um sistema de representações que possibilita antecipar os comportamentos do outro grupo e programar suas estratégias de ação (Cabecinhas, 2009). As representações sociais imprimem, assim, direções nas relações intergrupais, assumindo três funções: seleção, justificação e antecipação. As representações sociais, desempenham uma função primordial no jogo das relações entre grupos, podendo ser mediadoras de categorias identitárias ou, ainda, serem construídas a partir de processos identitários (Vala, 1997). Essa inter-relação teórica possibilita compreendermos os processos de categorização, por exemplo. É a partir da representação que os sujeitos têm sobre determinados grupos sociais e, também, sobre determinadas formas e práticas de viver que eles podem se "definir" pertencentes ou não a determinados grupos (Elcheroth, Doise, \& Reicher, 2011).

Em revisão feita por Silva (2018), a articulação da teoria das representações sociais com o estudo da homofobia subdividiu-se em quatro núcleos temáticos: (1) expressão do preconceito e natureza da homossexualidade; (2) adoção homoparental; (3) representações sociais da homossexualidade; (4) professores, representações sociais da homossexualidade e diversidade sexual. Os trabalhos objetivavam compreender as expressões do preconceito (sutil e flagrante) com base nas representações sobre a natureza da homossexualidade (representações sociais como produto e processo) e investigar as representações a respeito da homossexualidade (representações enquanto produto). 
A teoria das representações sociais tem procurado transcender a dicotomia indivíduo e sociedade no que diz respeito ao estudo de objetos socialmente polêmicos, no coração de conflitos identitários e intergrupais, como a homofobia. Buscando entender como os grupos pensam e lidam no dia-a-dia com as demandas criadas nas relações sociais, é importante perceber que as representações surgem e circulam em diferentes espaços, e isso inclui o ciberespaço.

Segundo Fragoso, Recuero e Amaral (2011), a internet permite identificar as diferentes interações sociais já existentes no plano offline. As redes sociais, por exemplo, constituem-se enquanto ambiente propício para que as representações sociais sejam encontradas e formadas por indivíduos e grupos, influenciando nas condutas, na atribuição de novos sentidos e servindo de referência para que as pessoas se posicionem em suas práticas sociais.

Maia e Rezende (2015), investigando diferentes plataformas digitais, perceberam que no Facebook, as pessoas se mobilizavam contra comentários racistas, mas não homofóbicos. Dantas e Abreu (2016) perceberam que os sentimentos de fúria presentes nos comentários imprimiam uma violência simbólica aos homossexuais. Os discursos homofóbicos nas redes sociais têm crescido abruptamente, e esses são apenas alguns trabalhos que demonstram que as redes sociais, especificamente o Facebook, têm se tornado um lugar de ódio e intolerância contra homossexuais e outros grupos discriminados. $O$ objetivo desta pesquisa foi analisar as diferentes formas de expressão da homofobia nas redes sociais. Buscou-se identificar os discursos justificadores e compreender em que esses posicionamentos estão ancorados.

\section{Método}

\section{Material de análise}

Trata-se de uma pesquisa de cunho quanti-qualitativo que teve postagens do Facebook como material de análise. O corpus da pesquisa foi constituído por 1.592 comentários e respostas a respeito de uma publicação, em formato de vídeo, postada pela página "Quebrando o Tabu". Nesse vídeo, o médico brasileiro Dráuzio Varella faz a seguinte pergunta a respeito da homossexualidade:

Eu vou te perguntar uma coisa: Que diferença faz para você, para sua vida pessoal, se o seu vizinho dorme com outro homem? Se a sua vizinha é apaixonada pela colega de escritório? Que diferença faz para você? Se faz diferença, procure um psiquiatra! Você não está legal! 
A página "Quebrando o Tabu" possui mais de 9 milhões de seguidores, é uma das páginas mais populares do Facebook e seu conteúdo polêmico (aborto, feminismo, homossexualidade, política etc.) gera diferentes opiniões. Em julho de 2017, a publicação possuía mais de 15 milhões de visualizações, 10 mil comentários e 402.706 compartilhamentos. Devido ao volume de material, foram selecionados os comentários com mais de 100 curtidas, resultando em 13 comentários e suas respectivas respostas descritos na Tabela 1. 
Tabela 1

Descrição dos Comentários Principais

\section{Comentários}

1 Se você assiste esse vídeo e mesmo assim não se sente envergonhado de prosseguir com aversão a gays, se interne.

2 Que diferença faz para você se João ama Joaquim? Que diferença faz para você se Maria na realidade é João. E Marcos na realidade é Patrícia. Que diferença faz para você, se Cláudio não gosta de ninguém (não sente atração sexual)? Que diferença faz para você se ontem Vivian gostava de Flávia e hoje gosta do Mario? E assim por diante. Eu mesmo posso responder, não faz nenhuma diferença, mas para eles, serem respeitados faz sim, e uma diferença absurda.

3 Gente tentando justificar a própria homofobia com ah, não faz diferença, mas [insira desculpa tosca] só me faz ver que vocês realmente deveriam procurar um psiquiatra, amigos.

4 Respondendo à pergunta: não faz diferença nenhuma se fosse apenas isso. Mas querem ensinar ideologia de gênero nas escolas, querem obrigar pastores e padres a fazer o casamento em suas igrejas. Aí é que está o problema. Querem ser o suprassumo da sociedade, aí não dá!

5 Esse vídeo deveria passar na TV constantemente.... Durante os intervalos da novela, futebol, café da manhã.... A porra toda.... Quem sabe as pessoas comecem a tomar conta, um pouquinho, da vida delas.

6 De fato, em nada me incômoda. Agora, quando isso chega ao ponto de insinuarem a desnecessidade de banheiros masculinos e femininos em escolas infantis, aí a situação é outra.

7 Se o seu vizinho dorme com outro homem e isso faz diferença na sua vida, pode ter a absoluta certeza você é aquela pessoa frustrada que se inveja das felicidades alheias!

8 Para mim não tem diferença nenhuma. Tenho amigos que dormem juntos e eu e minha esposa frequentamos a casa deles e eles a nossa numa boa. Agora me incomoda muito saber que tentam enfiar goela abaixo que homossexuais são o suprassumo... se um gay xingar normal. Se você xingar um gay por ele ter feito algo contra a ordem não pode é homofobia.

9 Eu quando criança nunca tinha visto homem com homem e nem mulher com mulher. E agora eu sou travesti. É simples, as coisas só acontecem de forma natural bestas. Parem que está feio! Se for para ser homem, vai ser homem nessa porra! Se for para ser mulher, vai ser mulher! E se for para ser gay, prepara o coração, por que muita gente vai morrer de ódio! É simples.

1 Vou te perguntar uma coisa. Que diferença faz para você, para sua vida pessoal, se

o o seu vizinho pode comprar um carro de luxo, se a sua vizinha é apaixonada por comprar joias e roupas de grife? Que diferença faz para você? Se faz diferença, procure um psiquiatra, você não está legal

Deixo essa reflexão, apenas ampliando o escopo da fala do doutor, que é importante no seguinte ponto: em que momento a liberdade de terceiros pode ser reduzida de acordo com sua opinião pessoal?

1 O melhor de tudo é que é uma pergunta tão simples e tão direta que os

1 homofóbicos de plantão nem estão comentando com aqueles textões enormes. Afinal não tem o que falar porque não faz diferença nenhuma

1 De fato, o que cada um faz da sua vida não diz respeito a ninguém! Mas também

2 ninguém é obrigada a achar lindo e aplaudir este tipo de coisa! É opinião! Ter opinião não é crime, e também não é caso de psiquiatra!

1 Realmente, não faz diferença nenhuma para mim! Desde que não queiram impor

3 isso de uma maneira normal para os meus filhos! 


\section{Procedimentos e análise de dados}

Os dados foram analisados com o auxílio do software IRAMUTEQ. O IRAMUTEQ possibilita um mapeamento léxico do corpus, indicando a existência de um "campo textual" ou de um espaço semântico específico. O software é de grande auxílio quando se tem um volume razoável de dados e quando se procura extrair do texto principais diferenças em termos de "mundos léxicos". Através de uma classificação estatística do texto, o software evidencia as palavras que the são mais características, realizando uma classificação hierárquica descendente (CHD). A CHD identifica os "mundos léxicos", resultando na construção de sentidos. Por meio desta análise é possível interpretar o sentido das palavras através dos seus contextos, nomeando e classificando as classes com base na interpretação dos dados (Camargo \& J usto, 2013).

\section{Resultados e Discussão}

O corpus apresentou 1.113 segmentos de textos (ST), com aproveitamento de 1.005 ST $(90,30 \%)$. Surgiram 39.735 ocorrências, sendo 4.957 palavras diferentes. Após a análise básica, o corpus foi submetido a uma classificação hierárquica descendente (CHD), resultando em três subcorpora e quatro classes, como pode ser observado no dendrograma ${ }^{1}$ (Figura 1 ). O primeiro eixo nomeado "limites do debate na esfera pública" é formado por duas classes: Classe 1, denominada "Respeito" (40\%), e Classe 2, "Debate políticoideológico" (22.1\%), O segundo eixo, formado pela Classe 3, "Influência da homossexualidade para as crianças" (12,9\%), diz respeito às questões de ordem "pública e privada" atualizadas no debate sobre a influência da homossexualidade para crianças. Por fim, o terceiro eixo, constituído pela Classe 4, "Acusação aos homossexuais de deturpação da igreja" (25\%), trata das questões entre a "igreja e o Estado". 
Figura 1 - Dendrograma da Classificação Hierárquica Descendente (CHD)

\begin{tabular}{|c|c|c|c|c|c|c|c|}
\hline \multicolumn{2}{|c|}{ Classe 1} & \multicolumn{2}{|c|}{ Classe 2} & \multicolumn{2}{|c|}{ Classe 3} & \multicolumn{2}{|c|}{ Classe 4} \\
\hline \multicolumn{2}{|l|}{$\begin{array}{c}\text { Respeito } \\
\mathbf{4 0 \%}\end{array}$} & \multicolumn{2}{|c|}{$\begin{array}{l}\text { Debate politico- } \\
\text { ideológico } \\
22,1 \%\end{array}$} & \multicolumn{2}{|c|}{$\begin{array}{c}\text { Influência da } \\
\text { homossexualidade } \\
\text { para as crianças } \\
12,9 \%\end{array}$} & \multicolumn{2}{|c|}{$\begin{array}{c}\text { Acusação aos } \\
\text { homossexuais de } \\
\text { deturpação da igreja } \\
25 \%\end{array}$} \\
\hline Palavra & $\chi^{2}$ & Palavra & $x^{2}$ & Palavra & $x^{2}$ & Palavra & $\chi^{2}$ \\
\hline Opinião & 51 & Dia & 27.73 & Sexual & 101.46 & Igreja & 212.05 \\
\hline Respeitar & 49.17 & Responder & 27.07 & Escola & 75.98 & Casar & 208.76 \\
\hline Vida & 40.3 & Defender & 23.63 & Orientação & 66.85 & Casamento & 105.71 \\
\hline Achar & 30.94 & Lado & 21.16 & Criança & 61.76 & Padre & 77.02 \\
\hline Entender & 26.95 & Explicar & 20.57 & Mudar & 60.81 & Pastor & 72.17 \\
\hline Mundo & 24.87 & Público & 20.57 & Ensinar & 52.84 & Ler & 49.84 \\
\hline Impor & 18.68 & Casa & 18.25 & Aula & 47.45 & Direito & 46.63 \\
\hline Bonito & 18.25 & Sofrer & 18.25 & Médio & 40.63 & Querer & 44.7 \\
\hline Minha opinião & 18.05 & Bolsonaro & 18.25 & Cor & 39.81 & Direito iguais & 44.34 \\
\hline Humano & 17.4 & Primo & 17.72 & Gênero & 39.71 & Passar & 38.47 \\
\hline Lindo & 17.09 & Inocente & 17.72 & Futuro & 33.82 & Civil & 33.41 \\
\hline Respeito & 16.88 & Guardar & 17.72 & Psicologia & 33.82 & Cristão & 30.26 \\
\hline Viver & 16.82 & Aproveitar & 17.72 & Colega & 33.24 & Obrigar & 29.84 \\
\hline Precisar & 15.5 & Certeza & 17.58 & Engravidar & 33.15 & Suprassumo & 29.56 \\
\hline Levar & 15.15 & Pessoal & 17.01 & sexo & 29.37 & Religioso & 24.52 \\
\hline
\end{tabular}

1. Para fins de ilustração foram retidas no dendrograma as 15 palavras com associação significativa mais forte para cada classe medida pelo qui-quadrado

\section{Classe 1: "Respeito"}

Formada a partir de 402 ST (40\%), os discursos presentes nessa classe destacam quatro ideias: (1) respeito à liberdade de opinião; (2) respeito à individualidade; (3) tolerância; (4) desrespeito não é opinião, é preconceito. A primeira, relaciona-se com o direito a expressar-se, contrário ou a favor e, mesmo assim, ser respeitado. São comentários ancorados na noção de liberdade de expressão e respaldados no artigo 19 da Declaração Universal dos Direitos Humanos, de 1948, que, em geral, diz: "todo homem tem o direito à liberdade de opinião e de expressão, o que implica o direito de não ser incomodado por suas opiniões". Nessa classe, os comentários são em defesa desse direito considerado básico. O não cumprimento ou privação desse direito seria considerado uma censura, por exemplo:

“Apenas respeite à opinião do outro e já está de bom tamanho. O problema é que ter opinião contrária hoje é ser 
homofóbico. Respeitem a opinião do outro poxa, cada um tem sua opinião sua crença, ninguém é obrigado aceitar nada não, mas respeitar sim, até porque respeito é universal. Cabe a cada um respeitar a opinião do outro e saber que talvez o que é certo para você, para o outro pode não ser".

"Concordo contigo, o problema maior é que as pessoas não podem dar opiniões contrárias, querem colocar uma ditadura na liberdade de expressão".

Em geral, são comentários que reivindicam o direito a expressar opinião individual, mesmo que se configure como homofóbica. Para essas pessoas, considerar a homossexualidade uma abominação, pecado ou anormalidade, trata-se de opinião individual, e não de homofobia.

O respeito à individualidade foi expresso, em geral, de duas maneiras. Pela expressão "minha opinião", buscando legitimar o direito e a liberdade em opinar e, de uma segunda forma, referente às "particularidades pessoais". A expressão "vida alheia", por exemplo, foi utilizada para enfatizar que a orientação sexual é algo pessoal e que não deve ser alvo de comentários. Por exemplo:

"É minha opinião, eu acho que cada um de nós deve cuidar de suas vidas e deixar a dos outros, me dou muito bem com meus vizinhos e para mim tanto faz se são gays ou heterossexuais, eu nunca procuro saber da vida de ninguém, pois somos livres para fazer aquilo que queremos".

"Ter opinião na vida alheia é falta do que fazer. Nunca vi um gay pedindo opinião sobre o que você acha da vida dele, das escolhas dele, do namorado dele".

A palavra "vida" tem uma conotação de individualidade. Esses comentários também reforçam a ideia de respeito, segundo a qual os homossexuais precisam ser respeitados por serem quem são. Todavia, apesar do eixo central estar relacionado com o respeito, muitos comentários mostraram circunstâncias específicas para isso ocorrer. Percebeu-se, por exemplo, que muitos falaram em respeitar, desde que isso não fosse de encontro a princípios pessoais:

“Não faz diferença, mas não acho bonito, não concordo com as práticas, não sou obrigada e nem por isso sou homofóbica, não bato, não xingo só não acho bonito, minha opinião".

"E me perdoa os contrários. Mas eu não concordar, não significa que não respeito. E ninguém é obrigado a aceitar nada, respeitando e mantendo milhares de quilômetros de distância já está de bom tamanho". 
Em comum, esses comentários trazem a ideia de que os homossexuais e suas práticas precisam ser "respeitados", desde que não interfiram na "minha vida" ou "na vida da minha família". Souza e Dinis (2010), a respeito dos discursos sobre homossexualidade e gênero na formação docente em biologia, perceberam expressões como: "não me importo", "indiferente" e "cada um cuida da sua vida", ancorando expressões de preconceito sutil. Segundo os autores, os sujeitos que se intitulavam indiferentes apresentavam justificativas nas quais era evidente a expressão preconceituosa, principalmente, com as pessoas consideradas mais "exageradas", pois não estariam respeitando os limites dos outros. Elas precisavam manter uma certa distância (dimensão de expressão sutil): "eles" (homossexuais) do lado deles e "eu" (heterossexual) do "meu". Borrillo (2009) argumenta que uma das formas mais sutis de homofobia denota esse caráter de tolerância, atribuindo aos homossexuais um lugar marginalizado e silencioso, de uma sexualidade considera incompleta ou secundária.

Por fim, a ideia de que desrespeito não é opinião, é preconceito, evidencia-se nos comentários não preconceituosos e em defesa da diversidade sexual. São conteúdos que possibilitam o debate sobre o que é opinião e o que é discurso de ódio. Abaixo, exemplos de comentários que se contrapõem às expressões homofóbicas, apresentadas anteriormente:

“Eu acho é bonito esse povo dizendo: não tenho nada contra gays, só tenho uma opinião contrária. Quando sua opinião mata pessoas, tem alguma coisa muito errada nisso!"

"Respeitar opinião é uma coisa, agora respeitar preconceito disfarçado de opinião jamais".

Os discursos de ódio são baseados na intolerância e, a respeito da homofobia, em sua maioria, possuem três características em comum: são de cunho religioso, possuem uma lógica heteronormativa e incitam a violência e, até mesmo, a morte. As redes sociais têm se constituído como um espaço fértil para esse tipo de discurso.

\section{Classe 2: "Debate político-ideológico"}

Os comentários referentes à Classe 2, formada por 220 ST (22.09\%), transitam por duas agendas político-ideológicas distintas, definidas, em geral, como progressistas e conservadoras, e evidenciam três ideias principais: (1) o público e o privado; (2) os conflitos em defesa de lados e posições políticas; (3) a mobilização em defesa da família e da heterossexualidade.

O público está relacionado com a esfera social, e o privado, com a intimidade. Vale pontuar que a esfera social deveria ser o lugar onde 
público e privado podem estar em união, afinal, é na esfera pública que se comunica o privado. Entretanto, apenas os homossexuais são "obrigados" a resguardar suas demonstrações de afeto para o ambiente privado (suas casas), bem longe da sociedade (Scardua \& Souza, 2006). Como exemplo:

“Antigamente não se via manifestações homossexuais. Por que será? Porque os gays eram gays respeitosos, sabiam seus limites e não lutavam para poder beijar em público, afinal ninguém fazia isso. Porém, depois da era Karl Marx, quando o esquerdismo ficou forte, os gays acharam que eram vítimas e começaram a lutar contra a família tradicional brasileira".

"Ter respeito é o que mais falta aos gays, ser gay e fazer o que quiser dentro de sua casa é direito de cada um. Mas se beijar e se tocar em público já é muito não?"

Os comentários mostram uma tentativa de regulação e eliminação das sexualidades não heterossexuais e estão presentes, também, no ambiente off-line, inclusive, por meios de agressões físicas. Borrillo (2009), a esse respeito, comenta:

Aceita na esfera íntima da vida privada, a homossexualidade torna-se insuportável quando reivindica publicamente sua equivalência à heterossexualidade. A homofobia é o medo de que essa equivalência seja reconhecida. Ela se manifesta, entre outras coisas, pela angústia de ver desaparecer a fronteira e a hierarquia da ordem heterossexual. (Borrillo, 2009, pp. 19-20).

As expressões homofóbicas não podem ser encaradas como "simples" exposição de opiniões, afinal, negligenciar esse fato é compartilhar de um pensamento excludente e heteronormativo, em que o sujeito desviante (homossexual) precisa ser reorientado, concertado e regulado através de comentários ou de violência física e psicológica.

Falar em conflitos e em defesas de lados e posições, característica principal da Classe 2, leva a um dos temas clássicos da psicologia social, os grupos. Na Classe 2, eles se dividiram entre favoráveis e desfavoráveis aos homossexuais e suas práticas e com base em um critério político: esquerda e direita. O objetivo não é discutir as raízes epistemológicas na distinção desses conceitos, mas compreendê-los enquanto categorias analíticas nos processos de categorização e pertença grupal que trazem consigo, uma vez que as pessoas se identificam e se diferenciam a partir deles.

A formação da identidade social e/ou grupal se constitui a partir dos processos de categorização social, que possibilita aos sujeitos dividirem o mundo social em duas categorias: o seu grupo e o grupo dos outros. A consciência, junto com a carga afetiva e emocional que 
essa pertença traz consigo, resulta nos processos de diferenciação grupal. Segundo a diferenciação grupal, o indivíduo tende a avaliar de forma positiva o grupo ao qual pertence e negativamente o outro grupo (Torres \& Camino, 2013). A clivagem política aparece no comentário abaixo:

“Bolsonaro, discípulo de Enéas, em mais de 27 anos não tem uma acusação de corrupção sequer. Tem 3 filhos honestos, que são contra o comunismo e defendem as causas mais sensatas e óbvias, mas que os esquerdopatas insistem em tratar como golpistas. Temam, esquerdistas, gayzistas, maconheiros e feministas, 2018 está chegando".

Os estudos a respeito do preconceito possuem uma relação intrínseca com os aspectos políticos, sociais e econômicos que servem inclusive de justificação e legitimação dos posicionamentos preconceituosos (Torres \& Camino, 2013).

As expressões flagrantes do preconceito contra alguns grupos ainda figuram no cenário nacional. Uma das hipóteses para esse fenômeno é o fato de que o grau de interiorização das normas antipreconceito determina sua expressão. Ainda não existe, por exemplo, uma lei de criminalização da homofobia, como a Lei no 7.716/89 que criminaliza o racismo. Dessa forma, os sujeitos não precisam se enquadrar ou se preocupar com a manutenção de um status de não preconceituoso. Ao contrário, eles se apoiam nos seus grupos de pertencimento para atacar os homossexuais.

Uma das características dos atuais grupos conservadores é a defesa da família e da heterossexualidade - não qualquer família, mas o típico modelo tradicional. Seus fundamentos são a moral e os "bons costumes", usados, inclusive, para justificar e regular as sexualidades não heterossexuais (Jinkings et al., 2016). Abaixo, alguns exemplos desse eixo:

"Família: e não fugir aos instintos normais do corpo e da alma. Papai e mamãe, o resto é passageiro e tentação do diabo".

"Você confiaria um viado e viciado dentro da sua casa com seus filhos? Tenho uma amiga que um amigo viciado entrou na casa dela e tentou roubar uma coisa. Estou falando de caráter ou a falta dele e em 39 anos de vida o que vi, são que esses seres não são dignos".

Esses comentários, ancorados em aspectos ético-morais e religiosos reforçam a figura do homossexual como mau caráter, desrespeitoso e sem valor, além de "fraco espiritualmente", pois se corrompeu dos instintos normais do corpo e da alma (Lacerda et al., 2002; Pereira, Torres, Pereira, \& Falcão, 2011). Já a homossexualidade é aquela que 
irá destruir as famílias, acabar com a concepção de masculino e feminino e influenciar na orientação sexual das crianças.

\section{Classe 3 - "I nfluência da homossexualidade para as crianças"}

Constituída por 130 ST (12.94\%), a Classe 3 apresenta dois aspectos importantes a serem discutidos: (1) influência do estilo de vida homossexual para as crianças; (2) ensino e debate sobre diversidade sexual. Especificamente, trata do papel que os professores exercem na formação das crianças.

$\mathrm{Na}$ psicologia social, o tema da influência social está relacionado ao modo como a convivência social é capaz de influenciar na formação dos valores, das crenças, das normas sociais, das atitudes sociais e das opiniões pessoais (Gouveia, 2013). Na Classe 3, com base nos comentários, a influência social é compreendida como a capacidade de conseguir "transformar uma criança em homossexual" ou fazê-la "virar gay". São comentários ancorados nas crenças de que a orientação sexual pode ser influenciada se não existir um referencial masculino e feminino. Os comentários a seguir são exemplos dessas relações:

“Ensinar a respeitar é uma coisa, querer por kit gay e dizer que é normal os colegas do mesmo sexo se beijarem é outra! Eu não dei opinião na forma de vida de ninguém né? Quer dar o cu para homem que dê. Mas ensinar isso para o meu filho como se fosse normal, nunca. O povo não tem noção e nem senso. Daqui a pouco zoofilia vai ser considerado normal e vão querer apresentar uma cartilha para ensinar as crianças que isso é normal, tudo tem limite".

"Se ensinar que é normal ele pode ser influenciado a se tornar gay, da mesma forma que se você ensinar que roubar é bom, ele provavelmente roube. Então não vejo problema em ensinar que aquilo é errado, sendo assim ele provavelmente não irá se torna".

Destacam-se as representações da homossexualidade como algo que não é "normal" e dos homossexuais como promíscuos e doentes, a comparação com a zoofilia (parafilia) é um exemplo (Lacerda et al., 2002).

Como as redes sociais são ambientes polarizados, existe um grupo de pessoas que discorda da ideia de influência ou reorientação sexual. Essas pessoas percebem, ao contrário, o ensino e o debate sobre a diversidade sexual como uma das estratégias para o combate e enfrentamento ao preconceito. Seus comentários questionam os discursos homofóbicos e estão em consonância com os grupos que 
lutam para mostrar o quanto a homofobia se constitui enquanto um problema social, cabendo à escola ser um espaço de inclusão e conscientização crítica no desenvolvimento de práticas ligadas ao respeito, à diversidade e aos direitos humanos (Junqueira, 2009), apesar dos retrocessos que a educação tem vivido. Abaixo, exemplos dos comentários do segundo aspecto da classe 3 :

"A ideia de ensinar sobre homossexualidade não é mostrar pornô e sim dizer e explicar a homossexualidade de um modo biológico. Você tem que ensinar uma criança que a homossexualidade existe e que é normal em várias espécies, e ao longo da história humana também".

"Me ensinaram desde pequeno sobre sexo heterossexual, e eu não sou hétero. Fora o fato de que gênero e orientação sexual tem tanto a ver com psicologia quanto biologia e até onde eu sei, escola é um lugar que você recebe informação, e biologia é uma matéria obrigatória, incluindo a parte de sexo".

Apesar da escola não ser a principal responsável para explicar sobre identidades sociais e outros temas ligados à diversidade sexual, é preciso ressaltar que o ensinamento ali transmitido tem efeito na vida e nas histórias pessoais, constituindo-se de forma significativa nas relações sociais (Louro, 1999). Espera-se, com esses comentários em defesa de um ensino que respeita as diferenças e as individualidades, que a educação cumpra o seu papel de preparar os estudantes para a cidadania, aumentando a capacidade de crítica para o diálogo de temas complexos e na seleção das informações em tempos de notícias falsas (Reis \& Eggert, 2017).

\section{Classe 4: "Acusação aos homossexuais de deturpação da igreja"}

Formada por 251 ST (22.09\%.), a discussão em torno dessa classe evidencia as ideias segundos as quais (1) os homossexuais querem direitos demais (suprassumo) e; (2) querem impor suas práticas dentro da igreja. A religião e as crenças religiosas possuem um papel de destaque na compreensão da homofobia. Segundo Pereira (2004, p. 54), a pertença a uma religião "pode envolver os mesmos conjuntos de leis psicossociais que organizam os processos afetivos e cognitivos que justificam as diferenças sociais existentes e que dão suporte aos processos de exclusão social". As crenças religiosas, por exemplo, são utilizadas para justificar e ancorar os posicionamentos preconceituosos, além de influenciar a representação que as pessoas possuem a respeito da homossexualidade (Lacerda et al., 2002; Pereira et al., 2011). 
A respeito da primeira ideia, segundo a qual os homossexuais querem direitos demais, os comentários com expressões flagrantes de preconceito aparecem ancorados, principalmente, na ideia de que todos os seres humanos são iguais. Investigando quais seriam os direitos reivindicados pelos homossexuais que os colocavam na posição de "suprassumo" segundo a percepção dos internautas, identifica-se a busca pelo casamento igualitário, como pode ser visto abaixo:

“Parabéns. Querem tratar gays acima de tudo como se eles fossem o suprassumo. São todos humanos como os héteros são, nada a mais que isso. Em uma democracia você pode discordar daquilo que você não acha correto, aqui você não pode nem dizer que não concorda com a prática homossexual que já lhe chamam de homofóbico. Ditadura gay não".

"Quer saber a diferença? A diferença está em nenhum pai torcer para que seu filho seja um. No tocante a casar na igreja, assim como vocês querem respeito, respeitem também as igrejas. O regimento das igrejas vem da bíblia e a mesma não aceita esse tipo de conduta".

Ainda com base nesse direito considerado "demais", surge uma segunda discussão referente à imposição de práticas (homossexuais) dentro da igreja. É importante lembrar que o movimento LGBT não reivindica o casamento religioso. Levanta-se a hipótese, para pesquisas futuras, de que os rumores difundidos nas redes sociais têm servido de base para que comentários e homofóbicos sejam ancorados e propagados, como mostra abaixo:

"Eu só quero saber se todos que comentaram aqui concordam com o que houve em uma igreja nos estados unidos em que um casal gay queria casar lá e os pastores explicaram que a religião deles não concorda com a união gay e não podiam fazer o casamento. Os gays entraram com um processo, resultado: eles agora não querem mais fazer casamento algum, e era uma igreja muito requisitada. Legal isso né".

Os homossexuais e suas práticas representam uma ameaça para diferentes grupos fundamentalistas religiosos. Trata-se de uma ameaça simbólica que pode ser fruto dos rumores, trazendo consigo a crença de que eles querem influenciar, burlar e/ou infringir os valores heterossexuais, religiosos e conservadores.

Os comentários com expressões flagrantes ancoraram-se em explicações bio-religiosas e ético-morais. Neste tipo de ancoragem, 
há um amálgama entre religião e biologia. A religião é utilizada combinada a um argumento pretensamente biológico para ganhar força argumentativa na arena pública, por exemplo, segundo a criação divina (religião), "dois iguais não reproduzem", "isso vai contra a natureza" (biologia). A esse respeito, é possível lembrar o conceito de polifasia cognitiva que trata da coexistência de formas distintas de saberes no mesmo indivíduo ou grupo (Moscovici, 1976). As expressões sutis da homofobia ancoram-se nas crenças psicológicas e nas explicações clássicas da biologia (Lacerda et al., 2002). As expressões não preconceituosas ancoram-se nas explicações psicossociais, segundo as quais a homossexualidade é uma orientação sexual como qualquer outra (Lacerda et al., 2002), calcada na dimensão da não intencionalidade, como o desejo e a atração (Scardua \& Filho, 2006).

\section{Considerações Finais}

Esse trabalho teve como objetivo identificar as diferentes formas de expressão da homofobia em uma publicação de vídeo da página "Quebrando o tabu", além dos discursos justificadores utilizados para ancorar os comentários realizados. Foram identificadas expressões flagrantes por meio dos comentários explicitamente ofensivos e dos discursos de ódio; expressões sutis com formas simbólicas e/ou institucionalizadas; e expressões não preconceituosas, com os posicionamentos em defesa dos homossexuais e da homossexualidade.

Os discursos justificadores se dividiram em dois eixos: o primeiro, baseado nos valores de igualdade, composto por comentários que acusavam os homossexuais de buscarem direitos a mais ou que deslegitimavam a homofobia com o argumento de que "somos todos iguais"; o segundo, baseado nas normas cristãs e justificados com base na palavra de Deus.

Algumas limitações precisam ser pontuadas, como o fato de não ter sido explorada expressão ambivalente do preconceito; 0 aprofundamento dos aspectos ligados ao sexismo, visto que as expressões homofóbicas possuem raízes no preconceito contra as mulheres; além do diálogo com as teorias de gênero. Como pistas futuras, espera-se desenvolver um aprofundamento nas relações entre ancoragem e função justificadora das representações sociais, colocando em evidência diferenças em relação à homofobia contra gays e contra lésbicas (aspecto pouco explorado nesse estudo); a articulação entre ideologias políticas e homofobia, e um estudo diacrônico para evidenciar (ou não) uma mudança nas expressões da homofobia em ambientes virtuais. 


\section{Referências}

Adorno, T. W., Frenkel-Brunswik, E., Levinson, D., \& Sanford, R. N. (1950). The authoritarian personality. New York: Harper \& Row.

Bogardus, E. S. (1928). Immigration and race attitudes. Oxford, England: Heath.

Borrillo, D. (2009). Homofobia. In T. Lionço \& D. Diniz (Orgs.), Homofobia e educação: um desafio ao silêncio (pp. 15-46). Brasília: Letras livres.

Cabecinhas, R. (2009). Investigar representações sociais: metodologias e níveis de análise. In M. M. Baptista (Ed.), Cultura: metodologias e investigação (pp. 51-66). Lisboa: Ver o Verso Edições.

Camargo, B.V., \& Justo, A.M. (2013). IRAMUTEQ: um software gratuito para análise de dados textuais. Temas em Psicologia, 21(2), 513-518. doi: 10.9788/TP2013.2-16

Camino, L. (1996). Uma abordagem psicossociológica no estudo do comportamento político. Psicologia e Sociedade, (8), 16-42.

Costa, A. B., \& Nardi, H. C. (2015). Homofobia e preconceito contra diversidade sexual: debate conceitual. Temas em Psicologia, 23(3), 715-726. doi: 10.9788/TP2015.3-15

Dantas, W. M., \& Abreu, G. (2016). Homofobia não: violência simbólica e preconceito em uma comunidade ativista do Facebook. Temática, 12(6), 124-140. Recuperado de http://www. periodicos.ufpb. br/ojs/index. php/tematica/article/vi ew/29227

David, D. S., \& Brannon, R. (Eds.). (1976). The forty-nine percent majority: The male sex role. Addison Wesley Publishing Company.

Doise, W. (1982). L'explication en psychologie sociale. Paris: PUF.

Dollard, J., Doob, L., Miller, N. Mowrer, O.,\& Sears, R. (1939). Frustration and aggrezsion. New York: Yale University Press.

Elcheroth, G., Doise, W., \& Reicher, S. (2011). On the knowledge of politics and the politics of knowledge: How a social representations approach helps us rethink the subject of political psychology. Political Psychology, 32(5), 729-758. doi: 10.1111/j.1467-9221.2011.00834.x

Fernandes, S. C. S. (2011). Crenças raciais e infra-humanização: uma análise psicossocial do preconceito contra negros (Tese de Doutorado). Programa de Pós-Graduação em Psicologia, Universidade Federal da Bahia, Salvador, Bahia.

Fragoso, S., Recuero, R., \& Amaral, A. (2011). Métodos de pesquisa para internet (Vol. 1). Porto Alegre: Sulina.

Garth, T. R. (1930). A review of race psychology. Psychological Bulletin, 27(5), 329-356. doi: 10.1037/h0075064 
Gouveia, R. (2013). Influência Social. In L. Camino, A. R. R. Torres, M. E. O. Lima, \&M. E. Pereira. Psicologia Social: temas e teorias (Cap. 6, pp. 357-411). Brasília: Technopolitik.

Grupo Gay da Bahia. (2017). Relatório 2017 “Assassinatos de LGBT no Brasil". Bahia: GGB.

Herek, G. M. (2000). The psychology of sexual prejudice. Current Directions in Psychological Science, 9(1), 19-22. doi: 10.1111/1467-8721.00051

Herek, G. M. (2007). Confronting sexual stigma and prejudice: Theory and practice. Journal of Social Issues, 63(4), 905-925. doi: 10.1111/j.1540-4560.2007.00544.x

Hudson, W. W., \& Ricketts, W. A. (1980). A strategy for the measurement of homophobia. Journal of homosexuality, 5(4), 357-372. doi: 10.1300/J082v05n04_02

Jinkings, I., Doria, K., \& Cleto, M. (Org.). (2016). Por que gritamos golpe? para entender o impeachment e a crise política no Brasil. São Paulo: Boitempo.

Junqueira, R. D. (2009). Homofobia nas Escolas: um problema de todos. In R. D. Junqueira (Org.), Diversidade Sexual na Educação: problematizações sobre a homofobia nas escolas (pp. 13-51). Brasília: Ministério da Educação, UNESCO.

Junqueira, R. D. (2012). Homofobia: limites e possibilidades de um conceito em meio a disputas. Bagoas - Estudos Gays: Gêneros e Sexualidades, 1(1). Recuperado de https://periodicos.ufrn. br/bagoas/article/view/2256

Lacerda, M., Pereira, C., \& Camino, L. (2002). Um estudo sobre as formas de preconceito contra homossexuais na perspectiva das representações sociais. Psicologia: reflexão e crítica, 15(1), 165-178. doi: 10.1590/S0102-79722002000100018

Lehne, G. K. (1976). Homophobia among men. In D. S. Deborah, \& R. Brannon, The forty-nine percent majority: The male sex role, (pp. 66-88), Boston: Addison Wesley Publishing Company.

Logan, C. R. (1996). Homophobia? No homoprejudice. Journal of homosexuality, 31(3), 31-53. doi:10.1300/J082v31n03_03

Louro, G. L. (1999). Segredos e mentiras do currículo. Sexuālidade e gênero nas práticas escolares. In L. H. Silva (Org.), A escola cidadã no contexto da globalização. (pp. 33-47). Petrópolis: Vozes.

Maia, R. C. M., \& Rezende, T. A. S. (2015). Democracia e a ecologia complexa das redes sociais online: um estudo sobre discussões acerca do racismo e da homofobia. Intexto, (34), 492-512. doi: 10.19132/1807-8583201534.492-512

McConahay, J. B., \& Hough J r, J. C. (1976). Symbolic racism. Journal of social issues, 32(2), 23-45.

Moscovici, S. (1976). La psychanalyse, son image, son public. Paris: PUF. 
Pereira, A. S. L. S. (2004). Representações sociais do homossexualismo e preconceito contra homossexuais (Dissertação de mestrado). Universidade Católica de Goiás, Goiânia, GO, Brasil.

Pereira, C. R., Torres, A. R., Pereira, A., \& Falcão, L. C. (2011). Preconceito contra homossexuais e representações sociais da homossexualidade em seminaristas católicos e evangélicos. Psicologia: Teoria e Pesquisa, 27(1), 73-82. doi: 10.1590/S0102-37722011000100010

Pettigrew, T. F., \& Meertens, R. W. (1995). Subtle and blatant prejudice in Western Europe. European Journal of Social Psychology, 25(1), 57-75. doi: 10.1002/ ejsp.2420250106

Reis, T., \& Eggert, E. (2017). Gender ideology: a fallacy built around the brazilian Education Plans. Educação \& Sociedade, 38(138), 9-26. doi: 10.1590/es0101-73302017165522

Rios, R. R. (2007). O conceito de homofobia na perspectiva dos direitos humanos e no contexto dos estudos sobre preconceito e discriminação. In F. Pocahy (Org.), Rompendo o silêncio: homofobia e heterossexismo na sociedade contemporânea ( $p p$. 27-48). Porto Alegre: Nuances.

Scanlon, T. M. (2009). A dificuldade da tolerância. Novos EstudosCEBRAP, (84), 31-45. doi: 10.1590/S0101-33002009000200003

Scardua, A., \& Souza, E. A. D. Filho. (2006). O debate sobre a homossexualidade mediado por representações sociais: perspectivas homossexuais e heterossexuais. Psicologia: Reflexão e crítica, 19(3), 482-490. doi:10.1590/S010279722006000300017

Silva, A. M. T. B. D., Constantino, G. D., \& Premaor, V. B. (2011). A contribuição da teoria das representações sociais para análise de um fórum de discussão virtual. Temas em psicologia, 19(1), 233-242. Recuperado de http: // pepsic. bvsalud.org/scielo.php?script=sci_arttext\&pid=S1 413-389X2011000100018

Silva, L. B. (2018). Redes de ódio: um estudo sobre homofobia no Facebook (Dissertação de mestrado). Universidade Federal de Pernambuco, Recife, PE, Brasil.

Smith, K. T. (1971). Homophobia: A tentative personality profile. Psychological Reports, 29(3, pt. 2), 1091-1094. doi: 10.2466/pr0.1971.29.3f.1091

Souza, L.C., \& Dinis, N.F. (2010). Discursos sobre homossexualidade e gênero na formação docente em biologia. Pro-Posições, 21(3), 119-134. doi: 10.1590/S0103-73072010000300008

Torres, A. R. S., \& Camino, L. (2013). Grupos sociais, relações intergrupais e identidade social. In L. Camino (Org.), Psicologia Social: temas e teorias (pp. 515-539). Brasília, Technopolitik. 
Tajfel, H. (1982). Grupos humanos e categorias sociais. Lisboa: Livros Horizonte.

Turra, C., \& Venturi, G. (1995). Racismo cordial. São Paulo: Ática.

Vala, J. (1997). Representações sociais e percepções intergrupais, Análise Social, 32(140), 7-31. Recuperado de http: //analisesocial.ics.ul.pt/documentos/1221840494M6zFQ7x v9Rd55BV5. pdf

Weinberg, G. (1973). Society and the healthy homosexual. Oxford, England: Anchor.

\section{Endereço para correspondência Lawerton Braga da Silva}

Avenida Antônio Lira, 507, Casa 01, CEP 58039-050, João Pessoa - PB, Brasil

Endereço eletrônico: lawertonbraga@hotmail.com

Renata Lira dos Santos Aléssio

Universidade Federal de Pernambuco

Centro de Filosofia e Ciências Humanas, Programa de Pós-graduação em Psicologia Avenida da Arquitetura, s/n, 9o Andar, Departamento de Psicologia, Cidade Universitária, CEP 50740550, Recife - PE, Brasil

Endereço eletrônico: renatalir@gmail.com

Recebido em: 28/09/2018

Reformulado em: 29/01/2019

Aceito em: 07/02/2019

\section{Notas}

* Doutorando em Psicologia Social.

** Professora Adjunta e Doutora em Psicologia.

Financiamento: CAPES.

Este artigo de revista Estudos e Pesquisas em Psicologia é licenciado sob uma Licença Creative Commons Atribuição-Não Comercial 3.0 Não Adaptada. 